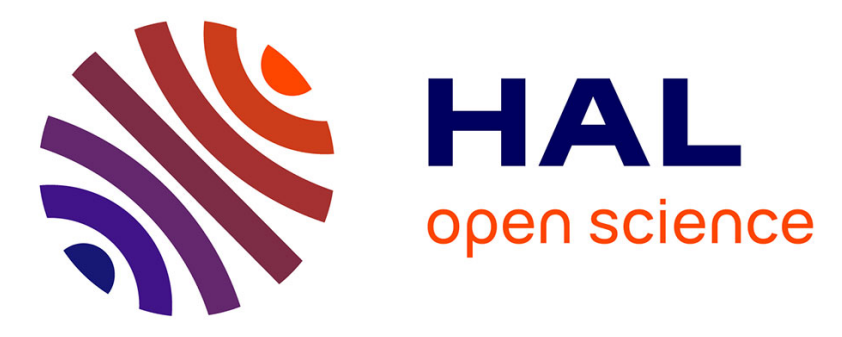

\title{
Stingless bees, Melipona fasciculata, as efficient pollinators of eggplant (Solanum melongena) in greenhouses
}

Patrícia Nunes-Silva, Michael Hrncir, Cláudia Silva, Yara Roldão, Vera Imperatriz-Fonseca

\section{To cite this version:}

Patrícia Nunes-Silva, Michael Hrncir, Cláudia Silva, Yara Roldão, Vera Imperatriz-Fonseca. Stingless bees, Melipona fasciculata, as efficient pollinators of eggplant (Solanum melongena) in greenhouses. Apidologie, 2013, 44 (5), pp.537-546. 10.1007/s13592-013-0204-y · hal-01201324

\author{
HAL Id: hal-01201324 \\ https://hal.science/hal-01201324
}

Submitted on 17 Sep 2015

HAL is a multi-disciplinary open access archive for the deposit and dissemination of scientific research documents, whether they are published or not. The documents may come from teaching and research institutions in France or abroad, or from public or private research centers.
L'archive ouverte pluridisciplinaire HAL, est destinée au dépôt et à la diffusion de documents scientifiques de niveau recherche, publiés ou non, émanant des établissements d'enseignement et de recherche français ou étrangers, des laboratoires publics ou privés. 


\title{
Stingless bees, Melipona fasciculata, as efficient pollinators of eggplant (Solanum melongena) in greenhouses
}

\author{
Patrícia Nunes-SiLva ${ }^{1}$, Michael HrNCIR ${ }^{2}$, Cláudia Inês da Silva ${ }^{1}$, \\ Yara Sbrolin RoLDÃo ${ }^{1}$, Vera Lucia IMPERATRIz-FonSECA ${ }^{2}$ \\ ${ }^{1}$ Departamento de Biologia, Faculdade de Filosofia, Ciências e Letras de Ribeirão Preto, Universidade de São \\ Paulo, Av. Bandeirantes, 3900-Bloco 2, 14040-901 Ribeirão Preto, SP, Brazil \\ ${ }^{2}$ Departamento de Ciências Animais, Universidade Federal Rural do Semi-Árido, Mossoró, RN, Brazil
}

Received 17 December 2012 - Revised 26 February 2013 - Accepted 7 March 2013

\begin{abstract}
Detailed studies of the behavior of pollinators allow insights into pollination mechanisms and may indicate which pollinators are more efficient for a particular plant species. Our aim was to evaluate if Melipona fasciculata is an efficient pollinator of eggplant (Solanum melongena L., Solanaceae) in greenhouses. We analyzed (1) the colony foraging pattern of $M$. fasciculata in greenhouses, (2) the behavior of bees during the visits to flowers, and (3) fruit set and fruit quality after different pollination treatments (hand pollination: autogamy, geitonogamy, xenogamy; bee pollination). Our results show that $M$. fasciculata is an efficient pollinator of eggplants and, consequently, may be a viable alternative to bumblebees in Brazil.
\end{abstract}

\section{Melipona fasciculata / stingless bee / eggplant / Solanum melongena / pollination}

\section{INTRODUCTION}

The successful reproduction of almost $90 \%$ of flowering plants depends on pollination (Ollerton et al. 2011), and, therefore, is fundamental for ecosystem functioning (Constanza, et al. 1997; Kevan 1999), and food industry (Klein et al. 2007). The necessary pollination services are provided by both native and managed pollinators, among which bees are the predominant agents (Ricketts et al. 2008). Although native bee species exist in almost all terrestrial ecosystems, only the honey bee Apis mellifera (Delaplane and Mayer 2000) and some bumble bee species (Bombus spp.) (Velthuis and van

Corresponding author: P. Nunes-Silva, pnsilva@usp.br

Manuscript editor: Klaus Hartfelder
Doorn 2006) are used for managed pollination in large scale.

Several plants, e.g. the Solanaceae, require a special kind of pollination termed "buzz pollination" (Buchmann 1983). Here, bees grab the anthers (or stamens) of a flower and vibrate them using their thoracic muscles. The thoracic vibrations are transmitted to the flowers and, consequently, provoke the release of pollen from the poricidal anthers (Buchmann 1983). Many bee species are not capable of performing buzz pollination, among them the honey bees (Buchmann 1983). Consequently, alternative pollinators, predominantly bumble bees, are used for the commercial pollination of those plant species that depend on buzz pollination (Raw 2000), such as tomatoes (Velthuis and van Doorn 2006) and eggplants (Free 1975; Abak et al. 1995, 2000; Gemmill-Herren and Ochieng 2008; Kowalska 2008). 
In Brazil, there are seven species of bumble bees. However, despite being abundant, they are not managed for crop pollination or any other purpose (Imperatriz-Fonseca et al. 2006). Because the introduction of exotic species, such as the European bumble bee Bombus terrestris, may cause serious damage of ecosystems and native organisms (Goulson 2003; Dafni et al. 2010), native bee species should be considered for commercial pollination (Kevan and ImperatrizFonseca 2002; Imperatriz-Fonseca et al. 2006). Here, a viable option in Brazil with respect to buzz pollination are native stingless bees (Apidae, Meliponini) of the genus Melipona, which are known to perform this behavior (Wille 1963; Proença 1992; Nunes-Silva et al. 2010). In the case of solanaceous crops, recent studies demonstrated that meliponine bees are efficient pollinators of tomatoes (Melipona quadrifasciata: Del Sarto et al. 2005; Bispo dos Santos et al. 2009; Hikawa and Miyanaga 2009; Melipona fasciculata: Venturieri et al. 2009; Nannotrigona perilampoides: Cauich et al. 2004; Palma et al. 2008), and eggplants (M. fasciculata: Venturieri et al. 2009). However, despite being managed for other purposes, such as honey production (Imperatriz-Fonseca et al. 2006; Slaa et al. 2006), the use of meliponine bees as crop pollinators is virtually absent (Imperatriz-Fonseca et al. 2006).

Investigating the behavior of bee species during flower visits can reveal their potential as pollinators for agriculture use (Primack 1993; Torchio 1994; Allen-Wardell et al. 1998). In the present study, we analyzed the behavior of $M$. fasciculata visiting flowers of eggplants (Solanum melongena) in order to evaluate if this bee species is a feasible alternative to the commercial use of bumble bees. Although eggplant flowers are highly self-compatible (reviewed by Kowalska 2008; Chen 2001), bee pollination significantly increases yield (Amoako and Yeboah-Gyan 1991; Abak et al. 1995, 2000; reviewed by Kowalska 2008; Gemmill-Herren and Ochieng 2008; Venturieri et al. 2009; Montemor and MalerboSouza 2009). We asked the following questions: (1) Is the foraging pattern of M. fasciculata colonies inside greenhouses adequate to promote pollination of eggplants? (2) Do the flowers' stigmata receive a larger amount of pollen grains when visited a single time or when visited several times by $M$. fasciculata foragers? (3) Does the number of pollen tubes in the styles increase with the number of flower visits? (4) Does the amount of pollen grains on the stigmata and/or the number of pollen tubes change with either the duration of buzzes generated by foragers, the number of buzzes, or the duration of flower visits? (5) To which extent do flower visits by $M$. fasciculata foragers influence fruit production?

\section{MATERIAL AND METHODS}

\subsection{Study site and species}

The present study was carried out in a greenhouse at the Department of Biology of the University of São Paulo in Ribeirão Preto, Brazil, between August and December 2009. Ambient temperatures outside of the greenhouse were recorded by a weather station (Oregon Scientific, WMR982) next to the experimental site (latitude: $21^{\circ} 9^{\prime} 48^{\prime \prime}$ South; longitude: $41^{\circ} 51^{\prime} 38^{\prime \prime}$ West; altitude: $580 \mathrm{~m}$ above sea level; time zone: GMT/ UTC $-03: 00$ hour). The greenhouse measured $6.4 \mathrm{~m}$ in width, $9 \mathrm{~m}$ in length (area $=57.6 \mathrm{~m}^{2}$ ), and had a maximum height of $3.5 \mathrm{~m}$. Its top cover was made of transparent, ultraviolet (UV) blocking polyethylene film (thickness: $150 \mu \mathrm{m}$ ), and its sides were closed with UVblocking shade cloth (mesh, $50 \%$ shade rate).

In the greenhouse, we planted 50 seedlings of $S$. melongena L. var. Embu (Solanaceae), two of which had to be removed during the experiment due to aphid infestation. In general, eggplants present floral heteromorphy with three types of flowers: longstyled, medium-styled, and short-styled flowers (Kowalska 2008). In our experiments, we analyzed only long-styled flowers because short-styled flowers present low fruit set (Kowalska 2008) and pollen germination is virtually absent (Rylski et al. 1984). Medium-styled flowers did not occur.

Approximately 3 months after planting the seedlings, we introduced a colony of $M$. fasciculata Smith (Apidae, Meliponini) into the greenhouse where it remained for 30 days. Because eggplant flowers provide only pollen for the bees (McGregor 1976), the colony was fed once every 15 days with $A$. mellifera honey. 
During the entire experimental period, the bees were allowed to freely visit the flowers.

\subsection{Floral biology of eggplant}

We observed the life time as well as the opening and closing times of 62 flowers. Additionally, we verified periodically if the pores of the anthers were open and registered their opening time.

\subsection{Colony foraging pattern}

During the first week after the bees started foraging at the eggplant flowers, we studied the foraging activity of the colony. We counted the number of bees leaving the nest, and the number of foragers returning with pollen. Additionally, we registered the frequency of flower visits by counting the number of bees on flowers seen while slowly walking along the rows of plants (transect method; Potts 2005), and the number of bees visiting the flowers of a single plant [mean number of flowers per plant: $6 \pm 1 ; N=6$ (one plant per day of observation); focal plant method; Potts 2005]. All observations were made for five minutes per hour between 06:00 and 18:00.

\subsection{Behavior of foragers}

Previously bagged flowers $(N=58)$ were exposed either to $8 \mathrm{~h}$ of bee-visitation $(N=16)$, or to a single beevisit $(N=42)$. After the visits, the flowers were bagged again until flower senescence. Single visits were filmed and subsequently analyzed with regard to the total duration of the visits (visit duration=time between first landing and leaving for the colony or another flower), and the time that bees actually remained on the flower (henceforth: time spent on a flower). In the course of a visit, bees frequently performed grooming flights. Thus, the time spent on a flower was calculated by subtracting the time spent with grooming flights from the visit duration. Additionally, we analyzed the number of buzzes made by the forager.

\subsection{Analysis of transferred pollen grains and pollen tube growth}

We collected the pistils of long-styled flowers $24 \mathrm{~h}$ after the bee visits and stored them in $70 \%$ alcohol for subsequent staining using a standard fluorescent technique (Martin 1959). Prior to staining, the pistils were diaphonized (treatment with $\mathrm{NaOH} 9 \mathrm{~N}$ solution to make pistils translucent and soft) and macerated (Martin 1959). Because eggplant pistils are very resistant to softening, we dissected them and submitted only one half to the maceration and staining procedure and posterior analysis. Thus, the total number of pollen grains and pollen tubes was estimated by duplicating the number of counted pollen grains and pollen tubes. For counting, we used digital images of the stigmata and the pistils taken with a fluorescent microscope (Zeiss Axioskope-Upright Fluorescent Microscope; Olympus DP-70 camera) at the Laboratory of Vegetal Morphology and Image (LAMOV), Institute of Biology, Federal University of Uberlândia, Brazil.

\subsection{Effect of bee pollination on fruit production}

To evaluate the effect of bee pollination on fruit production, we applied the following pollination treatments, divided into hand pollination treatments (October-November 2009) and bee pollination (December 2009): (1) Autogamy (A): hand pollination with pollen from the same flower $(N=128)$; (2) Geitonogamy $(\mathrm{G})$ : hand pollination with pollen from another flower of the same plant $(N=57)$; (3) Cross pollination (CP; xenogamy): hand pollination with pollen from the flower of a different plant $(N=27)$; (4) Bee pollination (B): free visitation by $M$. fasciculata $(N=$ 233); (5) Control (C): flowers that were neither hand pollinated nor bee pollinated; these flowers were bagged to exclude pollinators $(N=150)$. For the hand pollination treatments, performed between 08:00 and 12:00, we removed the anthers of a flower, placed them inside a $1.5 \mathrm{ml}$ plastic tube and agitated them to provoke pollen release. Subsequently, we collected the pollen with a toothpick and applied it to the stigma surface. Different toothpicks and tubes were used for each flower. In order to evaluate the efficiency of each pollination treatment, we analyzed the fruit set of the respective flowers.

\subsection{Data analysis}

The amount of transferred pollen and pollen tube growth after one or many bee visits was compared 
using the Mann-Whitney Rank Sum Test. The efficiency of the different pollination treatments was compared using the Kruskal-Wallis test (Dunn's method for post-hoc comparison of pairs). The relation between flower visitation frequency and colony foraging activity as well as the relation between bee behavior during flower visits and amount of transferred pollen and pollen tube growth was evaluated using Spearman Rank Correlation Analysis. Statistical analyses were performed using the software BioEstat, Statistica, and Sigma Plot. The $\alpha$-level of significance was $P \leq 0.05$. Throughout the text, data averages are presented as mean values \pm 1 st standard error.

\section{RESULTS}

\subsection{Floral biology of eggplant}

Most flowers (77.4\%) and anthers (58.1\%) were already opened at 06:00. In some cases, the anthers were closed at anthesis, and opened only at around 07:00 (22.6\%). At 16:00, the majority of flowers $(81.7 \%)$ had their petals closed. Most flowers opened for two $(43.5 \%)$ or three consecutive days $(41.9 \%)$. Few flowers opened for $1(4.9 \%)$ or 4 days $(9.7 \%)$.

\subsection{Foraging pattern of Melipona fasciculata}

Foraging activity (bees leaving the nest and foragers returning with pollen to the colony) was most intense in the morning and decreased gradually in the course of the day (Figure 1). Accordingly, flower visitation frequency was highest in the morning (Figure 1) and coincided with the number of bees exiting the hive and foraging for pollen (Spearman Rank Correlation: $r_{\text {visits-transect versus pollen }}$ entry $=0.58, r_{\text {visits-transect versus forager exit }}=0.68$, $r_{\text {visits-focal plant versus pollen entry }}=0.40, r_{\text {visits-focal plant }}$ versus forager exit $=0.51, P<0.05$; Figure 1 ).

\subsection{No relation between number of flower visits and amount of transferred pollen/pollen tube growth}

There was no statistically significant difference between the number of pollen grains deposited on the stigmata of flowers after one and several visits (one visit: $2,662 \pm 428$ pollen grains, $N=18$; several visits: $3,284 \pm 475$ pollen grains, $N=15$; Mann-Whitney Rank Sum Test: $P>0.05)$. Similarly, the number of pollen tubes in the styles did not differ between the two experimental situations (one visit: $718 \pm 41$ pollen tubes, $N=10$; several visits: $626 \pm 39$ pollen tubes, $N=16$; Mann-Whitney Rank Sum Test: $P>0.05)$. In both cases, pollen tubes reached and, consequently, fertilized the ovules (Figure 2).

\subsection{Relation between bee behavior during flower visits and amount of transferred pollen/pollen tube growth}

The foragers of $M$. fasciculata foragers visited eggplant flowers for $147 \pm 16 \mathrm{~s}(N=42)$. The average time spent on a flower (=visit duration minus time spent grooming) was $96 \pm$ $12 \mathrm{~s}(N=42)$. During the visits, the bees performed $68 \pm 10$ buzzes. The number of pollen grains transferred to the stigma did not change with visit duration, time spent on a flower, or number of buzzes (Table I). Pollen tube growth, on the other hand, was positively correlated with time spent on a flower and number of buzzes, but not with visit duration (Table II).

\subsection{The effect of bee pollination on fruit set and quality}

Pollination by $M$. fasciculata increased fruit set of eggplants by 29.5, 32.5, 45.7, and $12.1 \%$ compared to the control group without pollination, autogamy, geitonogamy, and cross pollination (fruit set: Control group: $23.3 \%, N=150$; Bee pollination: $52.8 \%, N=233$; Autogamy: $20.3 \%, N=128$; Geitonogamy: $7.1 \%, N=57$; Cross pollination: $40.7 \%, N=27$ ).

Unfortunately, only few fruits developed normally in our study, probably due to high ambient temperatures during the experimental period (Maximum temperatures between 33.5 and $35{ }^{\circ} \mathrm{C}$ ). Albeit the resulting low sample size, we found a positive effect of bee pollination on the weight of the normally developed 


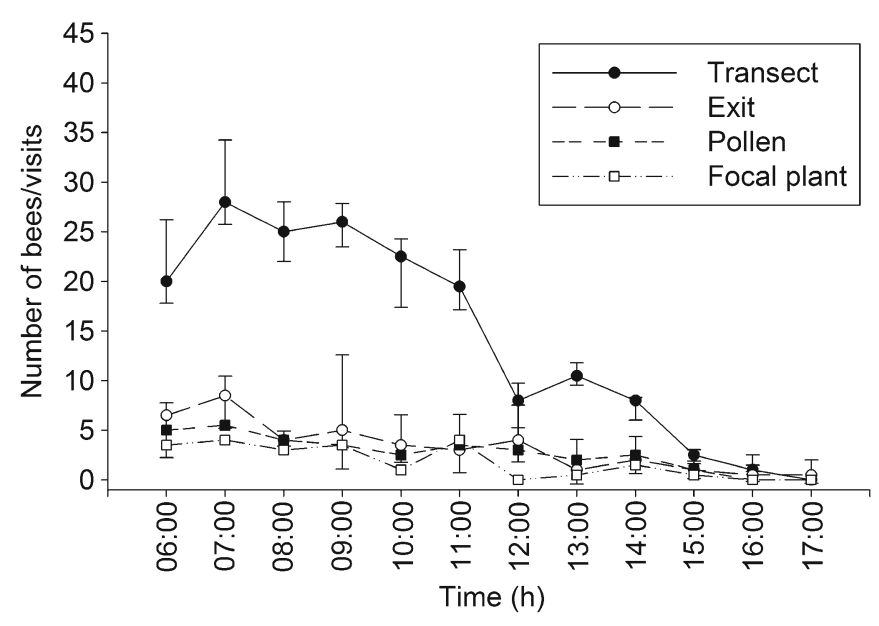

Figure 1. Number of Melipona fasciculata foragers leaving the hive (exit) and entering the hive with pollen (Pollen), and number of visits to eggplant (Solanum melongena L., Solanaceae) flowers along the transect and on a single plant per hour (observation time: 5 minutes $/ \mathrm{h}$ ) in the greenhouse. Data are presented as mean values \pm standard error.

fruits. Bee pollination (B) significantly increased fruit weight by $96 \%$ compared to the control group (C) and by $34 \%$ compared to the autogamy treatment (A) (Kruskal-Wallis test: $P<0.05$; Dunn's Pairwise Comparison: B versus C: $P<0.05$; B versus A: $P<0.05$; Table III, Figure 3). Although fruits deriving from bee pollinated flowers were on average $44 \%$ heavier than fruits from the geitonogamy treatment $(\mathrm{G})$ and $30 \%$ heavier than fruits from the cross pollination treatment $(\mathrm{CP})$, these differences were not statistically significant (KruskalWallis test, $P<0.05$; Dunn's Pairwise Comparison: $\mathrm{B}$ versus G: $P<0.05$; $\mathrm{B}$ versus CP: $P<0.05$; Table III, Figure 3).

\section{DISCUSSION}

Our results provide strong evidence that stingless bees, $M$. fasciculata, are efficient pollinators of eggplant ( $S$. melongena) in greenhouses. First, the foraging activity of this bee species highly overlapped with the opening time of the flowers. Second, a single flower-visit was sufficient for efficiently transferring pollen to the stigma, thus promoting pollination. And third, pollination by
M. fasciculata increased both yield and quality (weight) of the harvested fruits. This meliponine bee species, therefore, represents a viable alternative to bumblebees as pollinator of eggplant crop in Brazil, at least in greenhouses.

\subsection{Overlap between foraging activity and flower opening time}

The floral biology differs considerably among plants and the period during which stigmata are receptive is variable. Thus, when selecting a pollinator for a particular crop, it is crucial to choose a species whose foraging activity overlaps with the floral receptivity. Otherwise, results may be disappointing. The low efficiency of the stingless bee $M$. quadrifasciata as pollinator of tomatoes, for example, was attributed to the short overlap of only 30 min between the foraging peak (08:00 to 11:00) and the period that the stigma was most receptive (10:30 to 15:30) (Del Sarto et al. 2005).

In our study, the flight activity of $M$. fasciculata inside the greenhouse was most intense in the morning between 06:00 and 

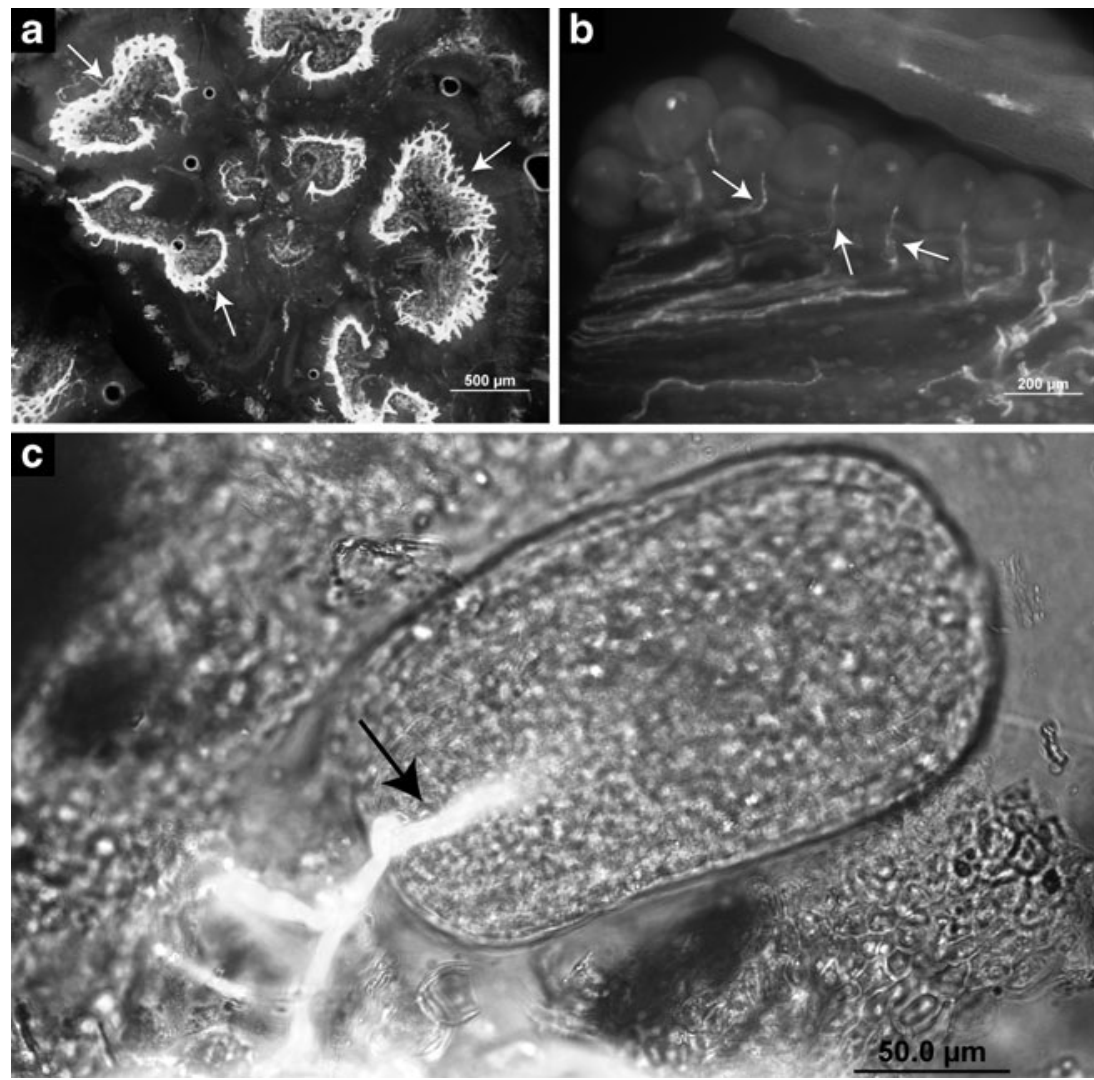

Figure 2. Pollen tubes (arrows) in eggplant ovary (Solanum melongena L., Solanaceae) $24 \mathrm{~h}$ after the visit by Melipona fasciculata. a Transversal cut showing pollen tubes. b Pollen tubes reaching ovules. c Pollen tube fecundating an ovule.

11:00 hours (Figure 1) and coincided with the opening time of eggplant flowers and anthers from 06:00 to 17:00 hours. This fit between colony foraging pattern and floral biology indicates M. fasciculata as potential pollinator of eggplant flowers.

Table I. Spearman correlation coefficients among the number of pollen grains on stigma after one visit of Melipona fasciculata to eggplant flowers (Solanum melongena L., Solanaceae), the visit duration, the number of buzzes performed by the bee, and the time the bee remained landed on flower. $N$ : sample size.

\begin{tabular}{llllr}
\hline & $\begin{array}{l}\text { Visit } \\
\text { duration }(\mathrm{s})\end{array}$ & $\begin{array}{l}\text { Number of } \\
\text { buzzes performed }\end{array}$ & $\begin{array}{l}\text { Time landed on } \\
\text { flower (s) }\end{array}$ & $N$ \\
\hline Number of buzzes performed & $0.91^{*}$ & - & - & 9 \\
Time landed on flower (s) & $0.91^{*}$ & $0.82^{*}$ & - & 9 \\
Number of grains on stigma & $0.63^{\text {ns }}$ & $0.55^{\text {ns }}$ & $0.65^{\text {ns }}$ & 9 \\
\hline
\end{tabular}

*Significant at $\alpha=0.05$

${ }^{\mathrm{ns}}$ Not significant at $\alpha=0.05$ 
Table II. Spearman correlation coefficients among the number of pollen tubes per style after one visit of Melipona fasciculata to eggplant flowers (Solanum melongena L., Solanaceae), the visit duration, the number of buzzes performed by the bee, and the time the bee remained landed on flower. $N=$ sample size.

\begin{tabular}{lllll}
\hline & $\begin{array}{l}\text { Visit } \\
\text { duration (s) }\end{array}$ & $\begin{array}{l}\text { Number of buzzes } \\
\text { performed }\end{array}$ & $\begin{array}{l}\text { Time landed } \\
\text { on flower (s) }\end{array}$ & $N$ \\
\hline Number of buzzes performed & $0.92^{*}$ & - & - & 17 \\
Time landed on flower (s) & $0.93^{*}$ & $0.91^{*}$ & - & 17 \\
Number of pollen tubes per style & $0.46^{\mathrm{ns}}$ & $0.56^{*}$ & $0.49^{*}$ & 17 \\
\hline
\end{tabular}

*Significant at $\alpha=0.05$

${ }^{\mathrm{ns}}$ Not significant at $\alpha=0.05$

\subsection{A single flower-visit by $M$. fasciculata is sufficient to promote pollination}

In addition to the concurrence between bee visits and flower receptivity, a crucial precondition for pollination is the deposition of enough conspecific pollen grains on the stigma of the visited flower (Vaissière et al. 2011). In our study, the number of pollen tubes formed in the style of a visited flower increased significantly with both the time a bee remained on a flower (time landed on flower) and the number of buzzes she performed during the visit (Table II). Hence, a minimum time on a flower is necessary to transfer enough pollen grains and guarantee pollination. Furthermore, we found similar amounts of pollen on the stigmata of eggplant flowers after a single visit $(2,662 \pm 428$ pollen grains) and after multiple visits $(3,284 \pm$ 475) of $M$. fasciculata. Thus, given that pollen tubes reach and fertilize the ovules both after a single and after multiple visits (Figure 2) and that the average number of seeds in eggplant fruits is 2,500 (McGregor 1976), a single bee visit can be considered sufficient to promote pollination. In line with this finding, studies on the pollination of tomato (Lycopersicon sculentum Mill., Solanaceae) indicate that a single flower-visit by bumble bees is sufficient to ensure pollination (Morandin et al. 2001; Nunes-Silva et al. 2012).

\subsection{Pollination by $M$. fasciculata increases fruit production}

The position of female and male organs of eggplant flowers allows for self-pollination (Chen 2001). Even so, fruit production increases when flowers are visited by bees (Amoako and YeboahGyan 1991; Free 1993; Abak et al. 1995, 2000; reviewed in Kowalska 2008; Gemmill-Herren and Ochieng 2008; Venturieri et al. 2009; Montemor and Malerbo-Souza 2009; Figure 3). In our study, pollination by $M$. fasciculata increased the fruit

Table III. Mean (mg), minimum (Min) e maximum (Max) weight of eggplant fruits (Solanum melongena L., Solanaceae) produced in the different treatments and respective standard errors (SE) and sample sizes $(N)$.

\begin{tabular}{lllll}
\hline & Mean $(\mathrm{mg}) \pm \mathrm{SE}$ & Min $(\mathrm{mg})$ & Max $(\mathrm{mg})$ & $N$ \\
\hline Autogamy & $311 \pm 10$ & 229 & 408 & 26 \\
Geitonogamy & $291 \pm 32$ & 203 & 353 & 4 \\
Cross pollination (Xenogamy) & $322 \pm 21$ & 261 & 482 & 11 \\
Melipona fasciculata & $418 \pm 9$ & 370 & 453 & 9 \\
Control (no visits) & $213 \pm 13$ & 188 & 257 & 5 \\
\hline
\end{tabular}




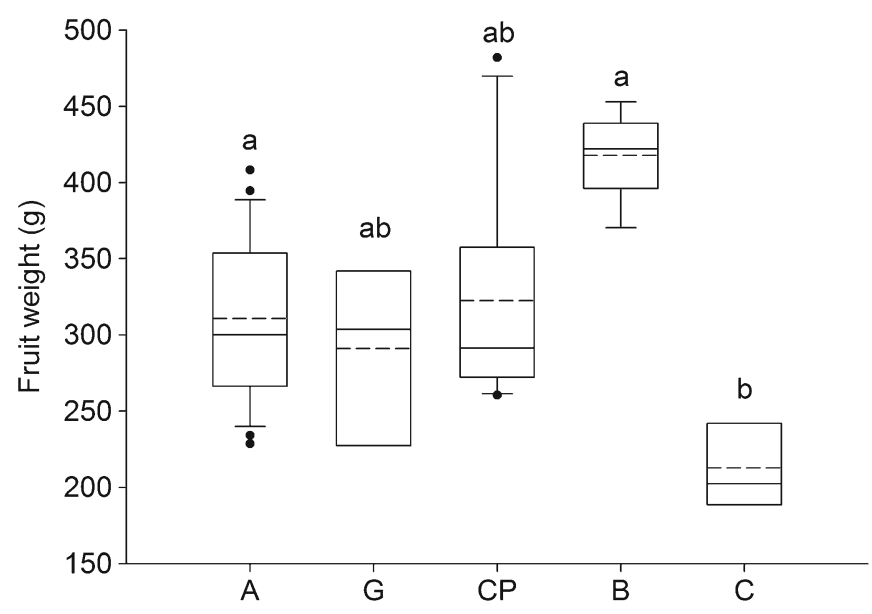

Figure 3. Mean weight of eggplant fruits (Solanum melongena L., Solanaceae) produced by autogamy $(A)$, geitonogamy $(G)$ and cross pollination $(C P$; xenogamy) through hand pollination, by Melipona fasciculata $(B$; Bee pollination) and with no pollination $(C$; control). Different letters $(a, b)$ indicate statistical differences at $P<$ 0.05 (Kruskall-Wallis, pair comparison: Dunn's method). Box plots box indicates the distribution of $50 \%$ of the values, horizontal full line indicates median, horizontal dashed line indicates mean, whiskers indicate standard error (above $90 \%$ and below $10 \%$ ), and spheres indicate outliers.

set of eggplants by $29.5 \%$ compared to the control group, which received no experimental pollination treatment but allowed for selfpollination at low rates. Our results confirm previous findings by Venturieri et al. (2009) for this bee species $(51 \%)$ as well as findings by Abak et al. (1995) for the bumble bee B. terrestris (23\%). In addition to fruit set, pollination by $M$. fasciculata increased fruit quality (measured as fruit weight) as compared to self-pollination (control group, autogamy treatment) (Table III; Figure 3; for similar findings on bumble bees see: Abak et al. 1995; 2000; Kowalska 2008).

\subsection{M. fasciculata as viable alternative to bumble bees}

The results of our study highlight $M$. fasciculata as efficient pollinator of eggplant in greenhouses. The positive effect of this bee species on both fruit set and fruit quality, which is similar to that found for pollination with $B$. terrestris, indicates that $M$. fasciculata can be used as viable alternative to bumble bees for pollination of solanaceous crops in Brazil. Additional studies are necessary to verify possible variations among colonies concerning their ability to adapt well in greenhouses and possible differences of foraging activity in the course of the year. Furthermore, it is necessary to study whether or not it is possible to use this bee species for eggplant pollination in open field.

\section{ACKNOWLEDGMENTS}

We thank Dr. Paulo Eugenio Alves Macedo de Oliveira for permission to use of his laboratory at Federal University of Uberlândia. We also thank "Fundação de Amparo à Pesquisa do Estado de São Paulo" (FAPESP) for funding (process number: 2007/ 03864-5 and 2004/15801-0).

Les abeilles sans aiguillon, Melipona fasciculata, pollinisent efficacement les cultures d'aubergine (Solanum melongena) sous serre

Melipona fasciculata / aubergine / culture sous serre / Brésil / pollinisation

Die Stachellose Biene Melipona fasciculata ist ein effizienter Bestäuber von Auberginen (Solanum melongena) in Gewächshäusern 
Melipona fasciculata / Stachellose Biene / Aubergine / Solanum melongena / Bestäubung

\section{REFERENCES}

Abak, K., Ozdogan, A.O., Dasgan, H.Y., Derin, K., Kaftanoglu, O. (2000) Effectiveness of bumble bees as pollinators for eggplants grown in unheated greenhouses. Acta Horticult. 514, 197-203

Abak, K., Sari, N., Paksoy, M., Kaftanoglu, O., Yeninar, H. (1995) Efficiency of bumble bees on the yield and quality of eggplants and tomato grown in unheated greenhouses. Acta Horticult. 512, 268-274

Allen-Wardell, G., Bernhardt, P., Burquez, A., Buchmann, S., Cane, J., et al. (1998) The potential consequences of pollinator declines on the conservation of biodiversity and stability of food crop yields. Conserv. Biol. 12(1), 8-17

Amoako, J., Yeboah-Gyan, K. (1991) Insect pollination of three solanaceous vegetable crops in Ghana with special reference to the role of African honey bee (Apis mellifera adansonii) for fruit set. Acta Horticult. 288, 255-259

Bispo Dos Santos, S.A., Roselino, A.C., Hrncir, M., Bego, L.R. (2009) Pollination of tomatoes by the stingless bee Melipona quadrifasciata and the honey bee Apis mellifera (Hymenoptera, Apidae). Genet. Mol. Res. 8, 751-757

Buchmann, S.L. (1983) Buzz pollination in angiosperms. In: Jones, C.E., Little, R.J. (eds.) Handbook of Experimental Pollination Biology, pp. 73-113. Scientific and Academic Editions, New York

Cauich, O., Quezada-Euán, J.J.G., Macias-Macias, J.O., Reyes-Oregel, V., Medina-Peralta, S., Parra-Tabla, V. (2004) Behavior and pollination efficiency of Nannotrigona perilampoides (Hymenoptera: Meliponini) on greenhouse tomatoes (Lycopersicon esculentum) in subtropical Mexico. J. Econ. Entomol. 97(2), 172-179

Chen, N.C. (2001) Eggplant Seed Production. Asian Vegetable Research and Development Center, Shanhua

Constanza, R., D'arge, R., Groot, R., Farberk, S., Grasso, M., Hannon, B., Limburg, K., Naeem, S., Paruelo, J., Raskin, R.G., Sutton, P., Van Den Belt, M. (1997) The value of the world's ecosystem services and natural capital. Nature 387, 253-260

Dafni, A., Kevan, P., Gross, C.L., Goka, K. (2010) Bombus terrestris, pollinator, invasive and pest: An assessment of problems associated with its widespread introductions for commercial purposes. Appl. Entomol. Zool. 45(1), 101-113

Delaplane, K.S., Mayer, D.F. (2000) Crop Pollination by Bees. CABI, Wallingford, UK

Del Sarto, M.C.L., Peruquetti, R.C., Campos, L.A.O. (2005) Evaluation of the neotropical bee Melipona quadrifasciata (Hymenoptera: Apidae) as pollinator of greenhouse tomatoes. J. Econ. Entomol. 98(2), 260-266

Free, J.B. (1975) Pollination of Capsicum frutescens L., Capsicum annuum L. and Solanum melongena L. (Solanaceae) in Jamaica. Trop. Agriculture 52(4), 353-357

Free, J.B. (1993) Insect Pollination of Crops. Academic, London, UK

Gemmill-Herren, B., Ochieng, A.O. (2008) Role of native bees and natural habitats in eggplant (Solanum melongena) pollination in Kenya. Agric. Ecosyst. Environ. 127(1-2), 31-36

Goulson, D. (2003) Effects of introduced bees on native ecosystems. Annu. Rev. Ecol. Evol. Syst. 34, 1-26

Hikawa, M., Miyanaga, R. (2009) Effects of pollination by Melipona quadrifasciata (Hymenoptera: Apidae) on tomatoes in protected culture. Appl. Entomol. Zool. 44(2), 301-307

Imperatriz-Fonseca, V., Saraiva, A.M., De Jong, D. (2006) Bees as Pollinators in Brazil: Assessing the Status and Suggesting Best Practices. Holos Editora, Ribeirão Preto

Kevan, P.G. (1999) Pollinators as bioindicators of the state of the environment: species, activity and diversity. Agric. Ecosyst. Environ. 74, 373-393

Kevan, P.G., Imperatriz-Fonseca, V.L. (2002) Pollinating Bees-The Conservation Link Between Agriculture and Nature. Ministry of Environment, Brasília

Kowalska, G. (2008) Flowering biology of eggplant and procedures intensifying fruit set-review. Acta Sci. Pol. Hortoru. 7(4), 63-76

Klein, A.M., Vaissière, B.E., Cane, J.H., SteffanDewenter, I., Cunningham, S.A., Kremer, C., Tscharntke, T. (2007) Importance of pollinators in changing landscapes for world crops. Proc. R. Soc. B 274(1608), 303-313. P R Soc

Martin, F. (1959) Staining and observing pollen tubes in the style by means of fluorescence. Stain. Technol. 34(3), 125-128

McGregor, S.E. (1976) Insect Pollination of Cultivated Crop Plants. USDA, Washington, DC

Montemor, K.A., Malerbo-Souza, D.T. (2009) Biodiversidade de polinizadores e biologia floral em cultura de berinjela (Solanum melongena). Zootec. Trop. 27(1), 97-103

Morandin, L.A., Laverty, T.M., Kevan, P.G. (2001) Effect of bumble bee (Hymenoptera: Apidae) pollination intensity on the quality of greenhouse tomatoes. J. Econ. Entomol. 94(1), 172-179

Nunes-Silva, P., Hrncir, M., Imperatriz-Fonseca, V.L. (2010) A polinização por vibração. Oecol. Aust. 14(1), 140-151

Nunes-Silva, P., Shipp, L., Hrncir, M., Imperatriz-Fonseca, V.L., Kevan, P.G. (2012) Influence of bumblebee behavior on tomato pollination: effects of number of flower visits and forager body size. Proceedings of $1 \mathrm{st}$ ApiEcoFlora Symposium, San Marino 
Ollerton, J., Winfree, R., Tarrant, S. (2011) How many flowering plants are pollinated by animals? Oikos 120, 321-326

Palma, G., Quezada-Euán, J.J.G., Reyes-Oregel, V., Meléndez, V., Moo-Valle, H. (2008) Production of greenhouse tomatoes (Lycopersicon esculentum) using Nannotrigona perilampoides, Bombus impatiens and mechanical vibration (Hym.: Apoidea). J. Appl. Entomol. 132, 79-85

Potts, S.G. (2005) Plant interface - pollinator interface. In: Dafni, A., Kevan, P.G., Husband, B.C. (eds.) Practical Pollination Biology, pp. 329-339. Enviroquest, Cambridge

Primack, R.B. (1993) Essentials of Conservation Biology. Sinauer, Massachusetts

Proença, C.E. (1992) Buzz pollination-older and more widespread than we think? J. Trop. Ecol. 8, 115-120

Raw, A. (2000) Foraging behaviour of wild bees at hot pepper flowers (Capsicum annuum) and its possible influence on cross pollination. Ann. Bot. 84, 487-492

Ricketts, T.H., Regetz, J., Steffan-Dewenter, I., Cunningham, S.A., Kremen, C., Bogdanski, A., Gemmill-Herren, B., Greenleaf, S.S., Klein, A.M., Mayfield, M.M., Morandin, L.A., Ochieng, A., Viana, B.F. (2008) Landscape effects on crop pollination services: are there general patterns? Ecol. Lett. 11, 499-515

Rylski, I., Nothmann, J., Arcan, L. (1984) Differential fertility in short-styled eggplant flowers. Sci. Hortic. 22, 39-46

Slaa, E.J., Sanchez, L.A., Malagodi-Braga, K.S., Hofstede, F.E. (2006) Stingless bees in applied pollination: practice and perspectives. Apidologie 37, 293-315

Torchio, P.F. (1994) The present status and future prospects of non-social bees as crop pollinators. Bee World 75, 49-53

Vaissière, B.E., Freitas, B.M., Gemmill-Herren, B. (2011) Protocol to Detect and Assess Pollination Deficits in Crops: A Handbook for its Use. FAO, Roma

Velthuis, H.H.W., Van Doorn, A. (2006) A century of advances in bumblebee domestication and the economic and environmental aspects of its commercialization for pollination. Apidologie 37, 421-451

Venturieri, G.C., Pires, N.V.C.R., Contrera, F.A.L. (2009) Management of stingless bee, Melipona fasciculata, for pollination of solanaceous crops in greenhouses. Proceedings of 41st Apimondia, Montpellier

Wille, A. (1963) Behavioral adaptations of bees for pollen collecting from Cassia flowers. Rev. Biol. Trop. 11(2), 205-210 